Check for updates

Cite this: RSC Adv., 2017, 7, 49473

\title{
Synthesis, structure and optical performance of red-emitting phosphor $\mathrm{Ba}_{5} \mathrm{AlF}_{13}: \mathrm{Mn}^{4+}$
}

\author{
Lin Qin, Peiqing Cai, Cuili Chen, Jing Wang and Hyo Jin Seo (DD*
}

$\mathrm{Mn}^{4+}$-activated cubic phase $\mathrm{Ba}_{5} \mathrm{AlF}_{13}$ red phosphors were prepared by the two-step coprecipitation method. The structural and optical features were characterized on the basis of X-ray diffraction (XRD), transmission electron microscopy (TEM), emission and excitation spectra, and luminescence decay curves. The $\mathrm{Ba}_{5} \mathrm{AlF}_{13}: \mathrm{Mn}^{4+}$ phosphors can be efficiently excited by near-UV to blue light and exhibit bright red emission at around $627 \mathrm{~nm}$, which is assigned to the ${ }^{2} E_{g} \rightarrow{ }^{4} A_{2 g}$ transition of the $3 d^{3}$ electrons in $\left[\mathrm{MnF}_{6}\right]$ octahedra. Temperature dependent emission spectra and decay curves from 10 to $550 \mathrm{~K}$ were measured to deeply understand the luminescence mechanism of $\mathrm{Mn}^{4+}$ in the $\mathrm{Ba}_{5} \mathrm{AlF}_{13}$ lattice. Notably, this novel red phosphor shows excellent anti-thermal quenching behaviour ( $700 \%$ of emission intensity at $300 \mathrm{~K}$ relative to $10 \mathrm{~K}$ ).

Received 11th August 2017

Accepted 28th September 2017

DOI: $10.1039 / \mathrm{c} 7 \mathrm{ra0} 8883 \mathrm{c}$

rsc.li/rsc-advances emitting phosphors for warm w-LEDs. ${ }^{6-8}$ However, further exploration of novel $\mathrm{Mn}^{4+}$-doped fluorides for red phosphors is deserved, and their properties should be investigated more deeply.

Here, in this work, we choose the $\mathrm{Mn}^{4+}$-doped fluoride $\mathrm{Ba}_{5} \mathrm{AlF}_{13}$ as a red-emitting phosphor, which has not yet been reported in the literature to our best knowledge. The $\mathrm{Ba}_{5}-$ $\mathrm{AlF}_{13}: \mathrm{Mn}^{4+}$ nanoparticles were synthesized via the two-step coprecipitation method. The phase formation, morphological features, excitation and emission spectra and thermal quenching behaviours were further investigated. The obtained product possesses a red line-emission spectrum with high thermal stability, which has the potential to enhance the color rendering index of an LED device.

\section{Experimental}

\subsection{Synthesis process}

The $\mathrm{Ba}_{5} \mathrm{AlF}_{13}: \mathrm{Mn}^{4+}$ nanoparticles were prepared via the two-step coprecipitation method as shown in Fig. 1. The chemical

A series of $\mathrm{Mn}^{4+}$ activated red phosphors with high luminous efficacy have been reported as candidates for red-emitting phosphors, especially, $\mathrm{Mn}^{4+}$-doped fluoride hosts. $\mathrm{Mn}^{4+}$-activated microcrystals of $\mathrm{K}_{2} \mathrm{TiF}_{6}$ were successfully synthesized by Zhu et al. in $2014 .^{5}$ The $\mathrm{K}_{2} \mathrm{TiF}_{6}$ microcrystals presented strong line emission with high luminescence quantum yield as high as 98\%, high thermal stability, and extremely high emission intensity. $\mathrm{Mn}^{4+}$-doped alkaline hexa-fluorides, $\mathrm{B}_{2} \mathrm{XF}_{6}: \mathrm{Mn}^{4+}(\mathrm{B}=$ $\mathrm{K}, \mathrm{Cs}, \mathrm{Rb} ; \mathrm{X}=\mathrm{Ti}$, Si and $\mathrm{Ge}$ ), are well known as excellent red-

Department of Physics and Interdisciplinary Program of Biomedical, Mechanical and Electrical Engineering, Pukyong National University, Busan 608-737, Republic of Korea.E-mail:hjseo@pkun.ac.kr

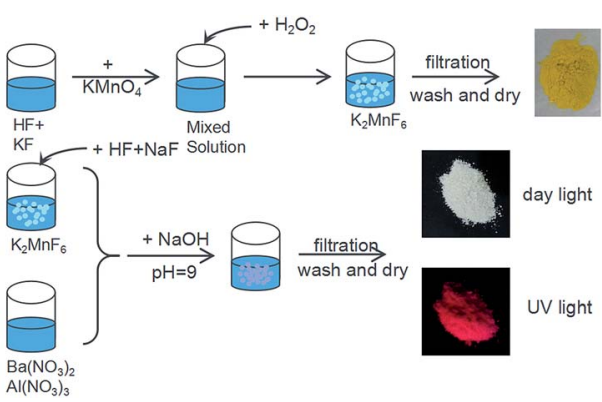

Fig. 1 Two-step synthesis of the $\mathrm{Ba}_{5} \mathrm{AlF}_{13}: \mathrm{Mn}^{4+}$ nanoparticles. 
reagents in the synthesis process were $\mathrm{KMnO}_{4}, \mathrm{KF}, \mathrm{HF}$, $\mathrm{Ba}\left(\mathrm{NO}_{3}\right)_{2}, \mathrm{Al}\left(\mathrm{NO}_{3}\right)_{3}, \mathrm{NaF}, \mathrm{H}_{2} \mathrm{O}_{2}$, and $\mathrm{NaOH}$. Firstly, the tetravalent manganese source $\mathrm{K}_{2} \mathrm{MnF}_{6}$ was synthesized according to Bode's method. ${ }^{9}$ The starting materials $\mathrm{KF}$ and $\mathrm{KMnO}_{4}$ were both dissolved in HF solution. The mixed solution was stirred for at least $30 \mathrm{~min}$ and then doped with $\mathrm{H}_{2} \mathrm{O}_{2}$ aqueous solution drop by drop until the yellow precipitate $\mathrm{K}_{2} \mathrm{MnF}_{6}$ was obtained. In the process of preparing the $\mathrm{Ba}_{5} \mathrm{AlF}_{13}: \mathrm{Mn}^{4+}$ nanoparticles, $\mathrm{K}_{2} \mathrm{MnF}_{6}$ was added to the HF solution, and then a double molar amount of NaF was added to yield the solution $\mathrm{A}$.

In a separate vessel, $\mathrm{Ba}\left(\mathrm{NO}_{3}\right)_{2}$ and $\mathrm{Al}\left(\mathrm{NO}_{3}\right)_{3}$ were both dissolved in water to yield solution $\mathrm{B}$. Then, the A and B solutions were mixed together, and an appropriate amount of $\mathrm{NaOH}$ was added drop-wise while stirring the solution to adjust the $\mathrm{pH}$ value to about 9. Finally, the resulting white slurry was filtered, washed several times using distilled water and then dried at $180{ }^{\circ} \mathrm{C}$ for $5 \mathrm{~h}$.

\subsection{Characterization}

The structure of the $\mathrm{Ba}_{5} \mathrm{AlF}_{13}: \mathrm{Mn}^{4+}$ nanoparticles was examined by XRD on a Rigaku D/Max 2000 diffractometer with operating parameters set to $40 \mathrm{kV}$ and $30 \mathrm{~mA}$. Transmission electron microscopy (TEM) was conducted to investigate the surface morphology of the samples. The samples were excited by using a $488 \mathrm{~nm}$ argon-ion laser and $355 \mathrm{~nm}$ pulsed Nd-YAG laser. The luminescence signal was detected using a photomultiplier tube (PMT, Hamamatsu, R928, Shizuoka, Japan) mounted on a $75 \mathrm{~cm}$ monochromator (Acton Research Corp. Pro-750). A $450 \mathrm{~W}$ Xe lamp dispersed by a $25 \mathrm{~cm}$ monochromator (Acton Research Corp. Pro-250) was used as a light source for the excitation and emission spectra. The time-resolved signal was digitized by means of a $500 \mathrm{MHz}$ Tektronix DPO 3054 scope.

\section{Results and discussion}

\subsection{Structural characterization}

Fig. 2 shows the XRD patterns of the $\mathrm{Ba}_{5} \mathrm{AlF}_{13}: \mathrm{Mn}^{4+}$ nanoparticles as functions of $\mathrm{Mn}^{4+}$ concentration. The standard PDF card (PDF\#44-1368) is displayed for comparison. All the

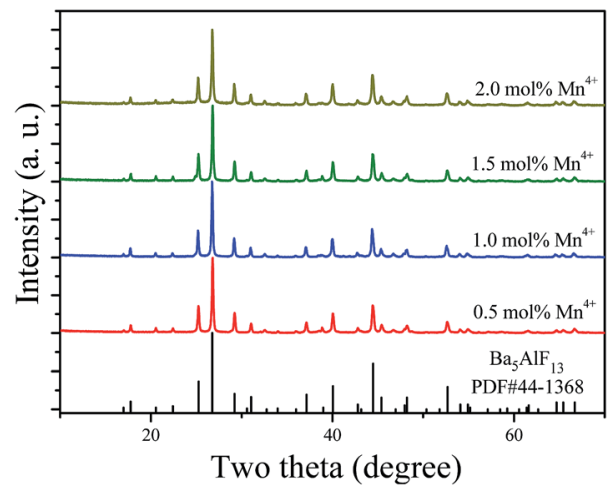

Fig. 2 X-ray diffraction patterns of $\mathrm{Ba}_{5} \mathrm{AlF}_{13}: \mathrm{Mn}^{4+}$ nanoparticles as functions of $\mathrm{Mn}^{4+}$ concentration. The PDF card is displayed for comparison. diffraction peaks match well with the standard PDF card, indicating that the $\mathrm{Ba}_{5} \mathrm{AlF}_{13}: \mathrm{Mn}^{4+}$ nanoparticles with different $\mathrm{Mn}^{4+}$ concentrations have been prepared as desired through the two-step coprecipitation method. The $\mathrm{Ba}_{5} \mathrm{AlF}_{13}: \mathrm{Mn}^{4+}$ nanoparticles crystallize in a cubic space group, $F d \overline{3} m$. The unit cell parameters are $a=b=c=17.378 \AA, \alpha=\beta=\gamma=90^{\circ}, V=$ $4427.83 \AA^{3}$ and $Z=3 .{ }^{10}$ Although $\mathrm{Ba}_{5} \mathrm{AlF}_{13}$ and $\mathrm{K}_{2} \mathrm{MnF}_{6}$ have different crystal structures and there is a mismatch in the valence states between $\mathrm{Al}^{3+}$ and $\mathrm{Mn}^{4+}$, the $\mathrm{Mn}^{4+}$ ions can also be incorporated into the host lattice of $\mathrm{Ba}_{5} \mathrm{AlF}_{13}$ due to the similar ionic radii of $\mathrm{Mn}^{4+}$ (coordination number $(\mathrm{CN})=6,0.53 \AA$ ) in $\left[\mathrm{MnF}_{6}\right]$ and $\mathrm{Al}^{3+}(\mathrm{CN}=6,0.535 \AA)$ in $\left[\mathrm{AlF}_{6}\right]^{.11}$

Fig. 3 shows the structural map of $\mathrm{Ba}_{5} \mathrm{AlF}_{13}$ and an illustration of an $\left[\mathrm{AlF}_{6}\right]$ octahedron according to the atomic coordinate data from ref. 10 . The $\mathrm{Ba}_{5} \mathrm{AlF}_{13}$ lattice contains only one unique crystallographic site of $\mathrm{Al}^{3+}$. All the $\mathrm{Al}^{3+}$ ions are located at the center of the regular octahedron $\left[\mathrm{AlF}_{6}\right]$, while $\mathrm{Ba}^{2+}$ forms $\left[\mathrm{Ba}_{(2)} \mathrm{F}_{8}\right]$ and $\left[\mathrm{Ba}_{(1)} \mathrm{F}_{10}\right]$ polyhedra connected together with the $\left[\mathrm{AlF}_{6}\right]$ octahedra. Since the ionic radius $(0.530 \AA)$ of $\mathrm{Mn}^{4+}$ is a little smaller than that $(0.535 \AA)$ of $\mathrm{Al}^{3+}$, the $\mathrm{Mn}^{4+}-\mathrm{F}^{-}$distance is probably smaller than the $\mathrm{Al}^{3+}-\mathrm{F}^{-}$distance. This means that a distorted system of $\left[\mathrm{MnF}_{6}\right]$ octahedra is preserved.

The actual size and morphology of the particles were analysed by TEM. Fig. $4 \mathrm{a}$ is a typical TEM image of the $\mathrm{Ba}_{5} \mathrm{AlF}_{13}$ :$\mathrm{Mn}^{4+}$ nanoparticles. The size of the nanoparticles is estimated to be about $120 \times 120 \mathrm{~nm}^{2}$. Fig. 4b shows the high-resolution TEM (HRTEM) image confirming the single-crystalline nature of the $\mathrm{Ba}_{5} \mathrm{AlF}_{13}: \mathrm{Mn}^{4+}$ nanoparticles. In addition, the selected area electron diffraction (SAED) pattern (the inset of Fig. 4b) exhibits the cubic symmetry ascribed to the $\mathrm{Ba}_{5} \mathrm{AlF}_{13}: \mathrm{Mn}^{4+}$ nanoparticles. The spacing of $3.33 \AA$ corresponds to the (333) reflections of the $\mathrm{Ba}_{5} \mathrm{AlF}_{13}: \mathrm{Mn}^{4+}$ nanoparticles.

\subsection{Spectroscopic properties of $\mathrm{Mn}^{4+}$ ions in $\mathrm{Ba}_{5} \mathrm{AlF}_{13}$ lattice}

The energy level scheme of $\mathrm{Mn}^{4+}$ in the lattice can be described by using the Tanabe-Sugano diagram and configuration coordinate model as shown in Fig. $5 \mathrm{a}$ and $\mathrm{b}$, respectively. The

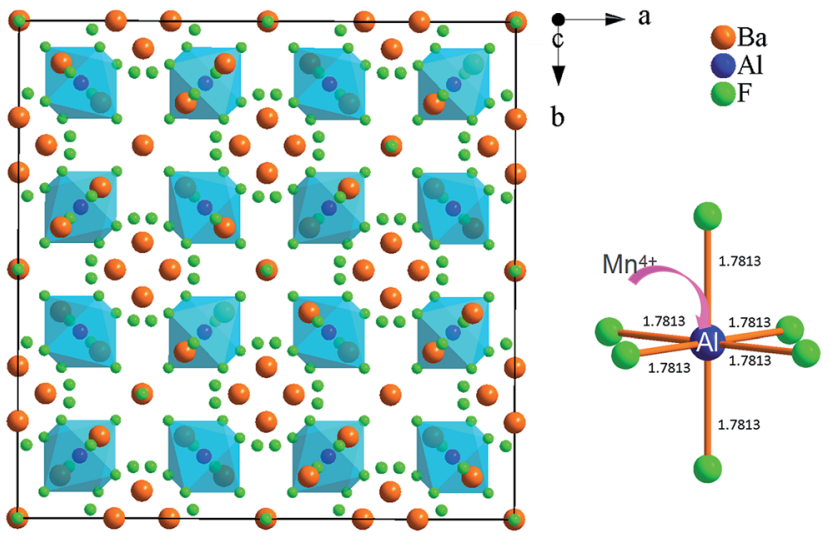

Fig. 3 Unit cell of the cubic-type $\mathrm{Fm} 3 \mathrm{~m}$ crystal structure of $\mathrm{Ba}_{5} \mathrm{AlF}_{13}$ projected along the $c$ axis and coordination of the $\mathrm{Al}^{3+} / \mathrm{Mn}^{4+}$ ions in this cubic-type crystal structure. $\mathrm{Ba}, \mathrm{F}$, and $\mathrm{Al} / \mathrm{Mn}$ ions are represented with orange, green, and blue spheres, respectively. 


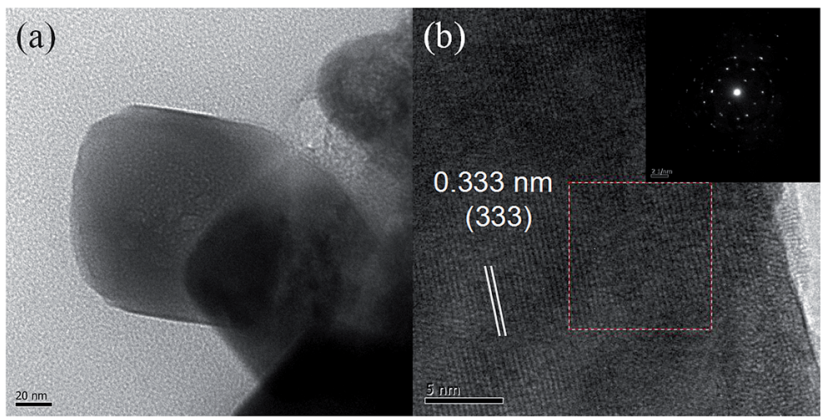

Fig. 4 Typical TEM image (a), HRTEM image (b), and the selected area electron diffraction pattern (the inset of b) of $\mathrm{Ba}_{5} \mathrm{AlF}_{13}: \mathrm{Mn}^{4+}$ nanoparticles.

luminescence characteristics of the $\mathrm{Mn}^{4+}$ ions depend highly on the crystal field strength except for the ${ }^{2} \mathrm{~T}_{1 \mathrm{~g}}$ and ${ }^{2} \mathrm{E}_{\mathrm{g}}$ states. The excitation spectrum of $\mathrm{Mn}^{4+}$ corresponds to the spin allowed ${ }^{4} \mathrm{~A}_{2 \mathrm{~g}} \rightarrow{ }^{4} \mathrm{~T}_{2 \mathrm{~g}}$ and ${ }^{4} \mathrm{~A}_{2 \mathrm{~g}} \rightarrow{ }^{4} \mathrm{~T}_{1 \mathrm{~g}}$ transitions, while the emission spectrum belongs to the spin-forbidden $\mathrm{d}-\mathrm{d}$ transition from the ${ }^{2} \mathrm{E}_{\mathrm{g}}$ state to the ${ }^{4} \mathrm{~A}_{2 \mathrm{~g}}$ state as in Fig. 5b. The lateral displacement between the parabolas of ground state ${ }^{4} \mathrm{~A}_{2 \mathrm{~g}}$ and excited state ${ }^{4} T_{1 g}$ (or ${ }^{4} T_{2 g}$ ) is large, while there is a small displacement between the parabolas of ${ }^{4} \mathrm{~A}_{2 \mathrm{~g}}$ and ${ }^{2} \mathrm{E}_{\mathrm{g}}$. A larger displacement implies a stronger electron-phonon interaction giving rise to a larger spectral bandwidth of the transition. ${ }^{12}$ Thus, intense excitation bands with relatively large bandwidths are expected for the transitions between these states, as well as sharp emission lines due to the ${ }^{2} \mathrm{E}_{g} \rightarrow{ }^{4} \mathrm{~A}_{2 \mathrm{~g}}$ transition of $\mathrm{Mn}^{4+}$.

The room temperature excitation spectrum of $\mathrm{Ba}_{5} \mathrm{AlF}_{13}: \mathrm{Mn}^{4+}$ $(0.5 \mathrm{~mol} \%)$ is shown in Fig. $5 \mathrm{c}$. The excitation spectrum is composed of two broad bands with the maxima at 360 and $460 \mathrm{~nm}$ corresponding to the spin allowed ${ }^{4} \mathrm{~A}_{2 g} \rightarrow{ }^{4} \mathrm{~T}_{1 g}$ and ${ }^{4} \mathrm{~A}_{2 g}$ $\rightarrow{ }^{4} \mathrm{~T}_{2 g}$ transitions of $\mathrm{Mn}^{4+}$, respectively. A slight splitting phenomenon can be observed in the excitation band corresponding to the ${ }^{4} \mathrm{~A}_{2} \rightarrow{ }^{4} \mathrm{~T}_{2}$ transition but is not observed for the ${ }^{4} \mathrm{~A}_{2} \rightarrow{ }^{4} \mathrm{~T}_{1}$ transition, probably due to a strong overlap with the re-absorption band of the ${ }^{4} \mathrm{~A}_{2} \rightarrow{ }^{2} \mathrm{~T}_{1}$ and ${ }^{4} \mathrm{~A}_{2} \rightarrow{ }^{2} \mathrm{E}$ transitions. ${ }^{13}$ The excitation spectrum indicates that the red phosphor doped with $\mathrm{Mn}^{4+}$ can be effectively excited by near UV/blue light, which is especially ideal for blue light excitation LED chips.

Contrary to the excitation spectrum, the emission spectrum belongs to the spin-forbidden $\mathrm{d}-\mathrm{d}$ transition from the ${ }^{2} \mathrm{E}_{\mathrm{g}}$ state to the ${ }^{4} \mathrm{~A}_{2 \mathrm{~g}}$ state of $\mathrm{Mn}^{4+}$, as shown in Fig. $5 \mathrm{~d}$. The emission spectrum consists of several sharp lines with the main peak at $627 \mathrm{~nm}$. In general, the zero-phonon line (ZPL) of $\mathrm{Mn}^{4+}$ in fluoride lattices is located at around $620 \mathrm{~nm}{ }^{3}$ The three peaks at wavelengths longer than $620 \mathrm{~nm}$ belong to Stokes $\nu_{6}\left(t_{2 u}\right.$ bending $), \nu_{4}\left(\mathrm{t}_{1 \mathrm{u}}\right.$ bending $)$, and $\nu_{3}\left(\mathrm{t}_{1 \mathrm{u}}\right.$ stretching) modes, whereas the two peaks at wavelengths shorter than $620 \mathrm{~nm}$ belong to antiStokes $\nu_{6}\left(\mathrm{t}_{2 \mathrm{u}}\right.$ bending) and $\nu_{4}\left(\mathrm{t}_{1 \mathrm{u}}\right.$ bending) modes. The ZPL is not observable for highly symmetrical lattice environments, for example, $\mathrm{Rb}_{2} \mathrm{SiF}_{6}: \mathrm{Mn}^{4+}$ and $\mathrm{BaTiF}_{6}: \mathrm{Mn}^{4+}$ red phosphors. ${ }^{6,14}$ More distorted coordination environments cause a stronger intensity of the ZPL line. ${ }^{6}$ The intense ZPL observed in the emission spectrum of the $\mathrm{Ba}_{5} \mathrm{AlF}_{13}: \mathrm{Mn}^{4+}$ nanoparticles indicates that the
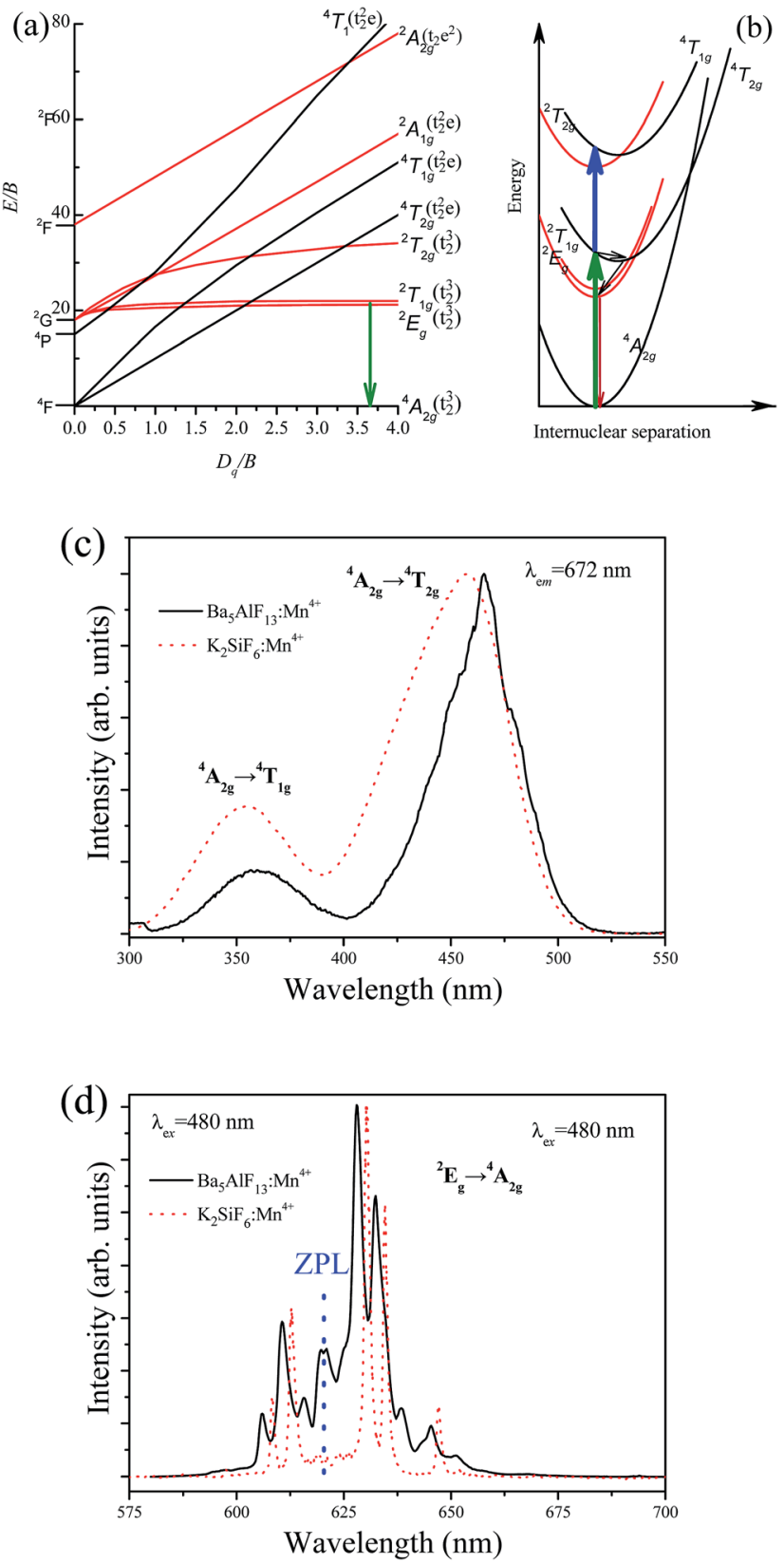

Fig. 5 (a) Tanabe-Sugano energy-level diagram for $d^{3}$ ions in the octahedrally coordinated environment. (b) Configurational coordination diagram for $\mathrm{Mn}^{4+}$ ions in fluoride hosts. Normalized excitation spectrum (c) and emission spectrum (d) of $\mathrm{Ba}_{5} \mathrm{AlF}_{13}: \mathrm{Mn}^{4+}$ (0.5 mol\%) compared with the well-known $\mathrm{K}_{2} \mathrm{SiF}_{6}: 1 \% \mathrm{Mn}^{4+}$ red phosphor.

$\mathrm{Mn}^{4+}$ ions experience a lower crystal field symmetry which is mainly due to the distorted $\left[\mathrm{MnF}_{6}\right]$ octahedron in the $\mathrm{Ba}_{5}{ }^{-}$ $\mathrm{AlF}_{13}: \mathrm{Mn}^{4+}$ lattice. According to ref. 6, the existence of ZPL emission in a $\mathrm{Mn}^{4+}$ doped phosphor can further improve the color rendering index. The CIE chromaticity coordinates of $\mathrm{Ba}_{5} \mathrm{AlF}_{13}: \mathrm{Mn}^{4+}$ are calculated to be $(x=0.691, y=0.31)$, which are close to the National Television System Committee (NTSC) standard values for red color $(x=0.67, y=0.33) .{ }^{15}$

The local crystal field strength $D_{\mathrm{q}}$ and two Racah parameters $B$ and $C$ can be introduced to describe the unique energy levels 
of the $\mathrm{Mn}^{4+}$ ions in the $\mathrm{Ba}_{5} \mathrm{AlF}_{13}$ lattice. ${ }^{2}$ The local crystal field strength $D_{\mathrm{q}}$ is given by the mean peak energy of the ${ }^{4} \mathrm{~A}_{2 \mathrm{~g}} \rightarrow{ }^{4} \mathrm{~T}_{2 \mathrm{~g}}$ transition as obtained by the following equation:

$$
D_{\mathrm{q}}=E\left({ }^{4} \mathrm{~A}_{2 \mathrm{~g}}-{ }^{4} \mathrm{~T}_{2 \mathrm{~g}}\right) / 10
$$

In this work, $10 D_{\mathrm{q}}$ is estimated to be $21500 \mathrm{~cm}^{-1}$ from the excitation spectrum. On the basis of the peak energy difference $\left(11900 \mathrm{~cm}^{-1}\right)$ between the ${ }^{4} \mathrm{~A}_{2 \mathrm{~g}} \rightarrow{ }^{4} \mathrm{~T}_{2 \mathrm{~g}}$ and ${ }^{4} \mathrm{~A}_{2 \mathrm{~g}} \rightarrow{ }^{4} \mathrm{~T}_{1 \mathrm{~g}}$ transitions, the Racah parameters $\mathrm{B}$ and $\mathrm{C}$ can be evaluated by the expressions:

$$
\begin{gathered}
\frac{D_{\mathrm{q}}}{B}=15(x-8) /\left(x^{2}-10 x\right) \\
\frac{E\left({ }^{2} \mathrm{E}_{\mathrm{g}}-{ }^{4} \mathrm{~A}_{2 \mathrm{~g}}\right)}{B}=\frac{3.05 C}{B}+7.9-\frac{1.8 B}{D_{\mathrm{q}}}
\end{gathered}
$$

where the constant $x$ is defined as

$$
x=\frac{E\left({ }^{4} \mathrm{~A}_{2 g}-{ }^{4} \mathrm{~T}_{1 g}\right)-E\left({ }^{4} \mathrm{~A}_{2 g}-{ }^{4} \mathrm{~T}_{2 g}\right)}{D_{\mathrm{q}}}
$$

From eqn (2)-(4), the crystal field parameters $B$ and $C$ are calculated to be 587 and $3800 \mathrm{~cm}^{-1}$, respectively, which are comparable to those of $\mathrm{K}_{2} \mathrm{SiF}_{6}: \mathrm{Mn}^{4+}\left(10 D_{\mathrm{q}}=23900 \mathrm{~cm}^{-1}, B=\right.$ $\left.605 \mathrm{~cm}^{-1}, C=3806 \mathrm{~cm}^{-1}\right) \cdot{ }^{16}$

The well-known $\mathrm{K}_{2} \mathrm{SiF}_{6}: 1 \% \mathrm{Mn}^{4+}$ red phosphor was prepared for comparison with the $\mathrm{Ba}_{5} \mathrm{AlF}_{13}: \mathrm{Mn}^{4+}$ phosphor. The excitation spectrum of $\mathrm{Ba}_{5} \mathrm{AlF}_{13}: \mathrm{Mn}^{4+}$ shifts to lower energy, by about $2400 \mathrm{~cm}^{-1}$, than that of $\mathrm{K}_{2} \mathrm{SiF}_{6}: \mathrm{Mn}^{4+}$ as shown in Fig. $5 \mathrm{c}$. This means that the crystal field strength of $\mathrm{Mn}^{4+}$ is weaker in the $\mathrm{Ba}_{5} \mathrm{AlF}_{13}$ lattice. As reported in ref. 3 , the $10 D_{\mathrm{q}}$ value depends on the metal-ligand distance according to the relationship $10 D_{\mathrm{q}}=$ $K / R^{n}$, where $K$ represents a constant and the value of $n$ is approximately 5 . As calculated in this work and with reference to ref. 3, the $\mathrm{Al}-\mathrm{F}$ bond distance in the $\left[\mathrm{AlF}_{6}\right]$ group is $1.781 \AA$ in $\mathrm{Ba}_{5} \mathrm{AlF}_{13}$, while the $\mathrm{Si}-\mathrm{F}$ bond distance in the $\left[\mathrm{SiF}_{6}\right]$ group is $1.682 \AA$. Hence, the crystal field strength of $\mathrm{Mn}^{4+}$ is weaker in the $\mathrm{Ba}_{5} \mathrm{AlF}_{13}$ lattice, which is consistent with the calculated $10 D_{\mathrm{q}}$ values above. As a consequence, the excitation spectrum of $\mathrm{Ba}_{5} \mathrm{AlF}_{13}: \mathrm{Mn}^{4+}$ shifts to lower energy. In addition, the luminescence intensity of the $\mathrm{K}_{2} \mathrm{SiF}_{6}: 1 \% \mathrm{Mn}^{4+}$ red phosphor is about three times higher than the phosphor prepared in this work.

Fig. 6 shows the emission spectra and decay curves of the $\mathrm{Ba}_{5} \mathrm{AlF}_{13}: \mathrm{Mn}^{4+}$ nanoparticles as functions of $\mathrm{Mn}^{4+}$ concentration. No difference in spectral features between different $\mathrm{Mn}^{4+}$ concentrations is observed in the emission spectra except for the relative intensities of the phonon lines. The emission intensity increases with increasing $\mathrm{Mn}^{4+}$ concentration from $0.1 \mathrm{~mol} \%$ and then reaches the maximum intensity at $0.5 \mathrm{~mol} \%$. With a further increase in $\mathrm{Mn}^{4+}$ concentration, the emission intensity starts to decrease gradually because of concentration quenching. ${ }^{17}$ However, the emission intensity ratio $(R)$ of the integrated ZPL intensity to the integrated $\nu_{6}$ line intensity depends on the $\mathrm{Mn}^{4+}$ concentration as shown in the inset of Fig. 6a. As mentioned above, the intensity of the ZPL depends highly on the local symmetry of the environment surrounding
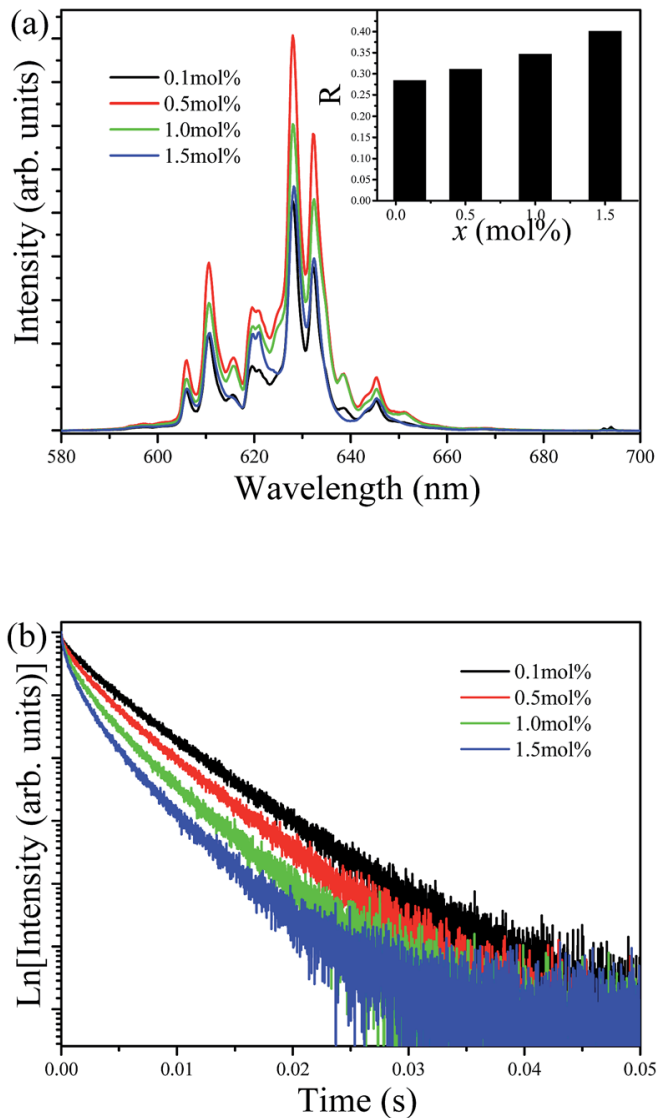

Fig. 6 Emission spectra (a) and decay curves (b) of $\mathrm{Ba}_{5} \mathrm{AlF}_{13}: \mathrm{Mn}^{4+}$ nanoparticles as functions of $\mathrm{Mn}^{4+}$ concentration.

$\mathrm{Mn}^{4+}$. The substitution of the larger $\mathrm{Mn}^{4+}$ ion for the smaller $\mathrm{Al}^{3+}$ ion gives rise to lattice distortion. Therefore, higher $\mathrm{Mn}^{4+}$ concentrations cause more distortion of the $\left[\mathrm{MnF}_{6}\right]$ octahedron, thus lowering the crystal field symmetry with larger values of $R$.

Fig. $6 \mathrm{~b}$ shows the luminescence decay curves of $\mathrm{Ba}_{5} \mathrm{AlF}_{13}$ :$\mathrm{Mn}^{4+}(0.1-1.5 \mathrm{~mol} \%)$ nanoparticles obtained by monitoring the $627 \mathrm{~nm}$ emission under excitation at $355 \mathrm{~nm}$. The average decay time $\tau$ can be calculated by using the following equation.

$$
\tau=\frac{\int_{0}^{\infty} t I(t) \mathrm{d} t}{\int_{0}^{\infty} I(t) \mathrm{d} t}
$$

The decay time decreases with increasing $\mathrm{Mn}^{4+}$ concentration and the decay curves gradually deviate from the single exponential. The decay times are estimated to be 8.03, 7.34, 6.07 and $5.13 \mathrm{~ms}$ for the $\mathrm{Mn}^{4+}$ concentrations of $0.1,0.5,1.0$ and $1.5 \mathrm{~mol} \%$, respectively. Samples with low $\mathrm{Mn}^{4+}$ concentrations feature reduced interactions between the $\mathrm{Mn}^{4+}$ ions, leading to nearly single exponential decay curves. However, with increasing $\mathrm{Mn}^{4+}$ concentration, the distance between the ions shortens; subsequently, energy transfer between the $\mathrm{Mn}^{4+}$ ions can occur, which provides an additional decay channel, leading to non-exponential decay curves. A possible explanation for this luminescence quenching is due to the higher nonradiative 
energy migration through direct transfer among the $\mathrm{Mn}^{4+}$ ions. $^{18,19}$

\subsection{Unusual temperature-dependent emission spectra}

Fig. 7a shows the emission spectra of $\mathrm{Ba}_{5} \mathrm{AlF}_{13}: \mathrm{Mn}^{4+}(0.5 \mathrm{~mol} \%)$ as functions of temperature in the temperature region $10-500 \mathrm{~K}$ under excitation at $488 \mathrm{~nm}$. As mentioned above, the emission lines are assigned to the spin-forbidden ${ }^{2} \mathrm{E}_{\mathrm{g}} \rightarrow{ }^{4} \mathrm{~A}_{2 \mathrm{~g}}$ transition of $\mathrm{Mn}^{4+}$, but can gain intensity by the activation of vibronic modes. ${ }^{20}$ Some features are worth noting:

(1) The emission spectra show different spectral features at different temperatures. At $10 \mathrm{~K}$, the dominant peaks are those on the low-energy side of the ZPL at $620 \mathrm{~nm}$, while at $T>100 \mathrm{~K}$ the emission lines become broader and appear not only on the low-energy side but also on the high-energy side, and are known as the Stokes and anti-Stokes emission lines, respectively. At low temperature, the systems are more likely to occupy the vibrational ground state and Stokes emission primarily occurs. However, when the temperature rises, the electrons have enough energy to populate the upper vibration states and relax back to the ground state of ${ }^{4} \mathrm{~A}_{2 \mathrm{~g}}$ with anti-Stokes emission. ${ }^{21}$

(2) Based on the temperature dependent emission spectra in Fig. 7a, the total emission intensity as a function of temperature is shown in Fig. 8. The emission intensity increases firstly and then decreases with further increase in temperature. The emission intensity of some previously studied luminescent phosphors consistently decreases with the increase of temperature which is mainly due to the increase of the non-radiative transition probability. ${ }^{22}$ However, differently from most oxide lattices, $\mathrm{Mn}^{4+}$-doped fluoride lattices exhibit anti-thermal quenching behavior. ${ }^{21,23,24}$ As shown in Fig. 8, the total integrated emission intensity of the ${ }^{2} \mathrm{E}_{\mathrm{g}} \rightarrow{ }^{4} \mathrm{~A}_{2 \mathrm{~g}}$ transition at $300 \mathrm{~K}$ is found to be increased by about $700 \%$ compared with the initial intensity at $10 \mathrm{~K}$ and then decreased at higher temperatures due to the intense non-radiative transition. It is suggested for $\mathrm{Ba}_{5}$ $\mathrm{AlF}_{13}: \mathrm{Mn}^{4+}$ that the increased emission intensity is due to
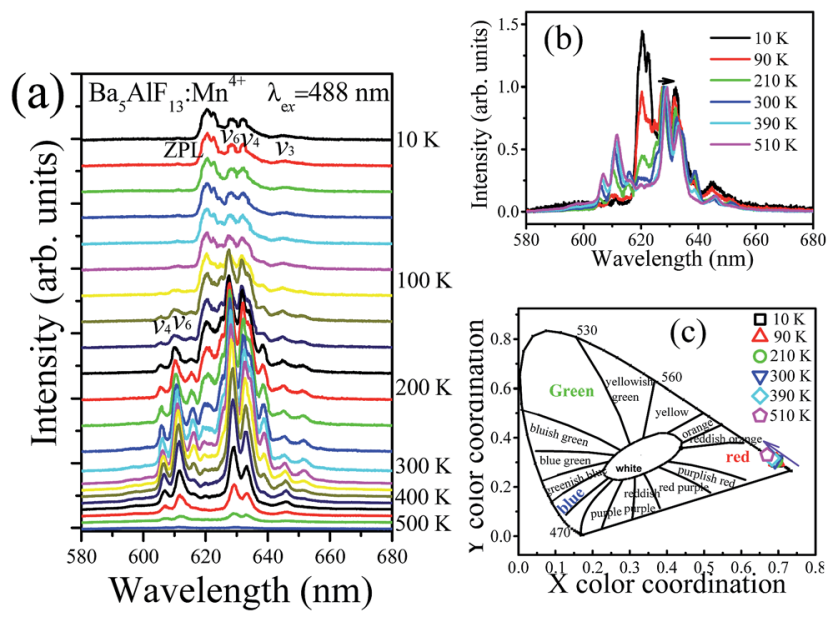

Fig. 7 Temperature dependent emission spectra (a) and normalized emission spectra (b) and $\mathrm{CIE}$ chromaticity coordinates (c) of $\mathrm{Ba}_{5}$ $\mathrm{AlF}_{13}: \mathrm{Mn}^{4+}(0.5 \mathrm{~mol} \%)$.

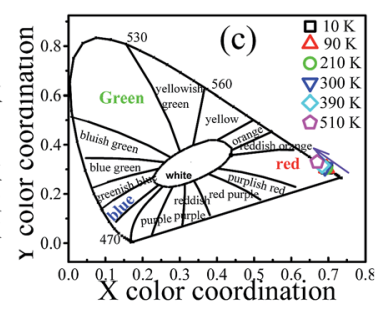

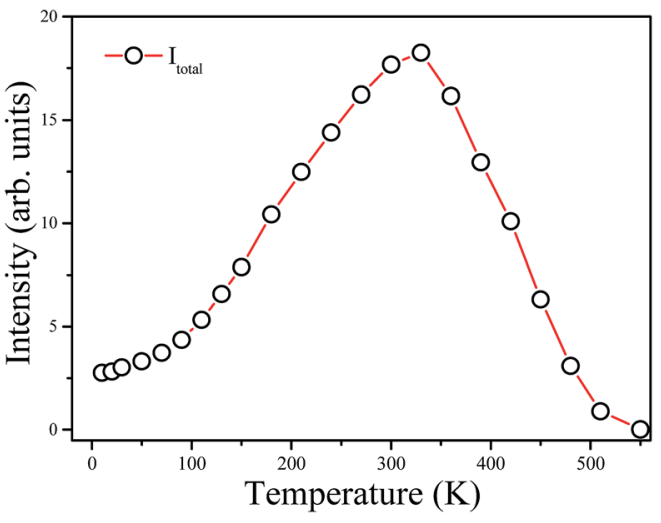

Fig. 8 Integrated intensity of total emission ( $\left.I_{\text {total }}\right)$ of $\mathrm{Ba}_{5} \mathrm{AlF}_{13}: \mathrm{Mn}^{4+}$ as a function of temperature.

expansion of the host lattice and the enhancement of the lattice vibration modes with increasing temperature. ${ }^{21}$

(3) It is observed that all the emission peaks show a tiny red shift and become gradually broader with increasing temperature (Fig. 7b). This is mainly due to the expansion of the unit cell and the enhancement of the vibration modes of the $\mathrm{MnF}_{6}{ }^{2-}$ octahedra in a hot environment. ${ }^{16}$

(4) The shifts of emission peaks and the changes in the relative emission intensity may induce variations of the chromatic coordinates of the phosphor. The dependences of the chromatic coordinates upon the temperature are calculated in Table 1 and shown in Fig. 7c. The $x$ values slightly decrease, while the $y$ values slightly increase, with increasing temperature. The variations in chromatic coordinates are caused by the red-shift of emission bands and the enhancement of anti-Stokes bands.

Fig. 9 shows the decay curves of the $627 \mathrm{~nm}$ emission under excitation at $355 \mathrm{~nm}$ as functions of temperature. The decays are single exponential at low temperature and become slightly non-exponential at high temperature. The decay times of the ${ }^{2} \mathrm{E}_{\mathrm{g}}$ state are calculated by using eqn (5). The decay times decrease monotonically from $15.2 \mathrm{~ms}$ at $10 \mathrm{~K}$ to $1.28 \mathrm{~ms}$ at $520 \mathrm{~K}$. The decay times calculated from the temperature-dependent decay curves are shown in Fig. 10a. The temperature dependent decay times of $\mathrm{Mn}^{4+}$ can be analyzed by the model for $\mathrm{Cr}^{3+}$ suggested by Grinberg. ${ }^{25} \mathrm{Cr}^{3+}$ is isoelectronic with $\mathrm{Mn}^{4+}\left(3 \mathrm{~d}^{3}\right.$ configuration). According to this model, an additional relaxation pathway (the spin-allowed ${ }^{4} \mathrm{~T}_{2 \mathrm{~g}} \rightarrow{ }^{4} \mathrm{~A}_{2 \mathrm{~g}}$ transition) occurs with increasing

intensity to the Stokes emission intensity

\begin{tabular}{lll}
\hline Temperature & $x$ & $y$ \\
\hline $10 \mathrm{~K}$ & 0.696 & 0.304 \\
$90 \mathrm{~K}$ & 0.695 & 0.305 \\
$210 \mathrm{~K}$ & 0.694 & 0.306 \\
$300 \mathrm{~K}$ & 0.691 & 0.309 \\
$390 \mathrm{~K}$ & 0.683 & 0.317 \\
$510 \mathrm{~K}$ & 0.670 & 0.330
\end{tabular}




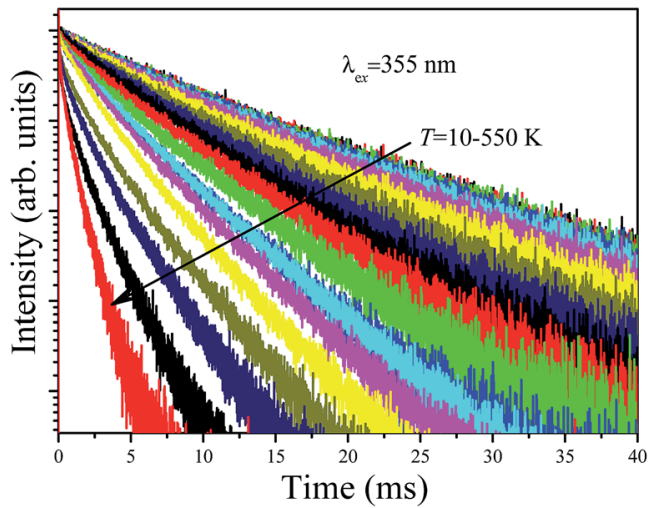

Fig. 9 Temperature dependent decay curves of $\mathrm{Ba}_{5} \mathrm{AlF}_{13}: \mathrm{Mn}^{4+} \mathrm{ob}-$ tained by monitoring the $627 \mathrm{~nm}$ emission under excitation at $355 \mathrm{~nm}$.
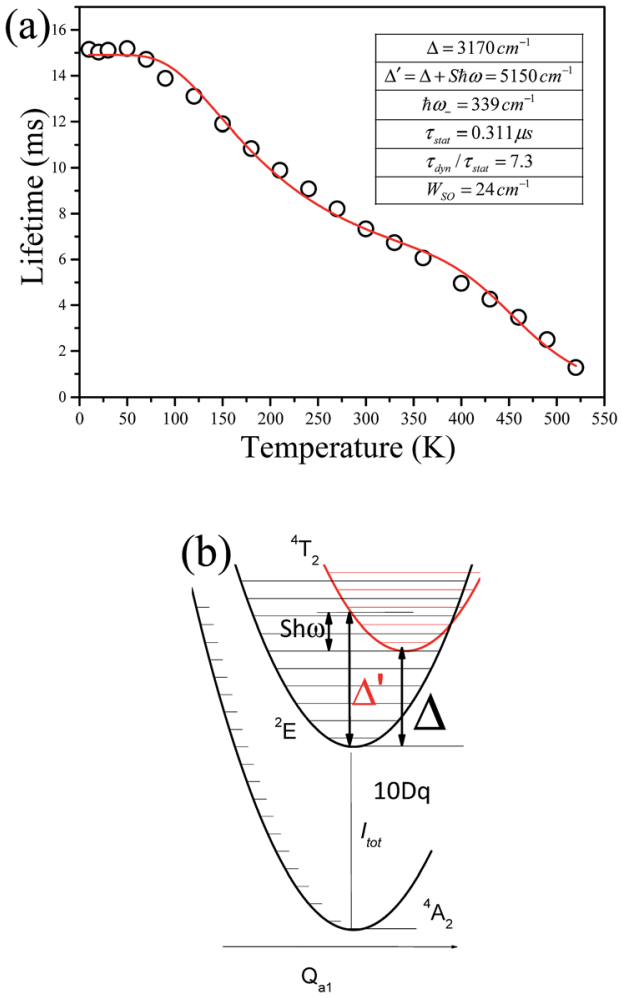

Fig. 10 (a) Decay times of the ${ }^{2} E$ state as a function of temperature $(10-550 \mathrm{~K})$ for $\mathrm{Ba}_{5} \mathrm{AlF}_{13}: \mathrm{Mn}^{4+}(0.5 \mathrm{~mol} \%)$. (b) Energy level diagram including the ground state and the lowest excited states without spinorbit interaction.

temperature and the temperature dependent decay times can be written by the following equation. ${ }^{26}$

$$
\tau=\frac{\tau_{\text {stat }}\left(1+\exp \left(-\frac{\hbar \omega_{-}}{k T}\right)+3 \exp \left(-\frac{\Delta}{k T}\right)\right)}{\left(1+\frac{\tau_{\text {stat }}}{\tau_{\text {dyn }}} \exp \left(-\frac{\hbar \omega_{-}}{k T}\right)\right)\left(\left(\frac{W_{\text {so }}}{\Delta^{\prime}}\right)^{2}+3 \exp \left(-\frac{\Delta}{k T}\right)\right)}
$$

where $\Delta^{\prime}$ represents the energy difference between the ${ }^{2} \mathrm{E}_{\mathrm{g}}$ and ${ }^{4} T_{2 g}$ states which can be calculated from the excitation spectrum. $\Delta$ is the energy difference between the minimum energy of the ${ }^{2} \mathrm{E}_{g}$ and ${ }^{4} \mathrm{~T}_{2 g}$ states. $\hbar \omega_{-}$is considered as a free parameter for the effective energy of phonons and $W_{\text {So }}$ is an average spin-orbit parameter. $\frac{\tau_{\text {stat }}}{\tau_{\text {dyn }}}$ is the ratio of the radiative decay times induced by static and dynamic processes. In addition, $\frac{1}{\tau_{\mathrm{dyn}}}$ is explicitly independent of temperature. ${ }^{21}$

The temperature dependent decay times are well fitted to eqn (6) and the fit result is shown by the solid red curve in Fig. 10a. The best fit result gives the parameters $\Delta^{\prime}=5150 \mathrm{~cm}^{-1}$, $\Delta=3170 \mathrm{~cm}^{-1}, \hbar \omega=339 \mathrm{~cm}^{-1}, W_{\mathrm{SO}}=24 \mathrm{~cm}^{-1}, \tau_{\text {stat }}=0.311 \mu \mathrm{s}$ and $\frac{\tau_{\mathrm{dyn}}}{\tau_{\mathrm{stat}}}=7.3$. The results of the temperature dependent decay times of the ${ }^{2} \mathrm{E}_{\mathrm{g}}$ state indicate that an additional relaxation pathway (the spin-allowed ${ }^{4} \mathrm{~T}_{2 g} \rightarrow{ }^{4} \mathrm{~A}_{2 g}$ transition) due to the spin-orbit interaction of ${ }^{2} \mathrm{E}_{g}$ and ${ }^{4} \mathrm{~T}_{2 g}$ states occurs with increasing temperature. As calculated, the obtained value of the radiative lifetime $\tau_{\text {stat }}$ corresponding to ${ }^{4} \mathrm{~T}_{2} \rightarrow{ }^{4} \mathrm{~A}_{2}$ is $0.311 \mu \mathrm{s}$, which is much shorter than the observed ${ }^{2} \mathrm{E} \rightarrow{ }^{4} \mathrm{~A}_{2}$ transition. Moreover, the effective spin-orbit coupling energy $\left(24 \mathrm{~cm}^{-1}\right)$ is much smaller than the spin-orbit coupling energy of the spinorbit interaction Hamiltonian generated by vibronic overlap integrals between the involved states as products of the electronic and vibronic wave functions. ${ }^{21}$

\section{Conclusions}

$\mathrm{Ba}_{5} \mathrm{AlF}_{13}: \mathrm{Mn}^{4+}$ nanoparticles were developed by the two-step coprecipitation method. Well-crystallized particles were obtained with sizes ranging from 300 to $500 \mathrm{~nm}$. The phosphors can be effectively excited by near UV - blue light and show bright red emission colors with several sharp lines of emission in the wavelength region $60-660 \mathrm{~nm}$. An intense ZPL emission at $620 \mathrm{~nm}$ is observed even at room temperature, which can be attributed to the incorporation of $\mathrm{Mn}^{4+}$ ions into highly distorted octahedral lattice sites. The temperature dependent luminescence indicates that the $\mathrm{Ba}_{5} \mathrm{AlF}_{13}: \mathrm{Mn}^{4+}$ red phosphor shows significant anti-thermal quenching behaviour to increase its emission intensity at $300 \mathrm{~K}$ relative to $10 \mathrm{~K}$. In addition, based on the temperature dependent decay curves, a modified dynamic model was constructed, indicating that an additional relaxation pathway (the spin-allowed ${ }^{4} \mathrm{~T}_{2 g} \rightarrow{ }^{4} \mathrm{~A}_{2 g}$ transition) occurs with increasing temperature.

\section{Conflicts of interest}

There are no conflicts to declare.

\section{Acknowledgements}

This research was supported by Basic Science Research Program through the National Research Foundation of Korea (NRF) funded by the Ministry of Education (2017R1D1A1B03029432). 


\section{References}

1 J. C. Boyer, F. Vetrone, L. A. Cuccia and J. A. Capobianco, J. Am. Chem. Soc., 2006, 128, 7444-7445.

2 M. G. Brika, S. J. Camardello, A. M. Srivastava, N. M. Avram and A. Suchocki, ECS J. Solid State Sci. Technol., 2016, 5, R3067-R3077.

3 Y. Jin, M. H. Fang, M. Grinberg, S. Mahlik, T. Lesniewski, M. G. Brik, G. Y. Luo, J. G. Lin and R. S. Liu, ACS Appl. Mater. Interfaces, 2016, 8, 11194-11203.

4 L. Huang, Y. W. Zhu, X. J. Zhang, R. Zou, F. J. Pan, J. Wang and M. M. Wu, Chem. Mater., 2016, 28, 1495-1502.

5 H. M. Zhu, C. C. Lin, W. Q. Luo, S. T. Shu, Z. G. Liu, Y. S. Liu, J. T. Kong, E. Ma, Y. G. Cao, R. S. Liu and X. Y. Chen, Nat. Commun., 2014, 5, 4312-4321.

6 M. H. Fang, H. D. Nguyen, C. C. Lin and R. S. Liu, J. Mater. Chem. C, 2015, 3, 7277-7280.

7 L. L. Wei, C. C. Lin, Y. Y. Wang, M. H. Fang, H. Jiao and R. S. Liu, ACS Appl. Mater. Interfaces, 2015, 7, 10656-10659.

8 T. Han, T. C. Lang, J. Wang, M. J. Tu and L. L. Peng, RSC Adv., 2015, 5, 100054-100059.

9 H. Bode, H. Jenssen and F. Bandte, Angew. Chem., 1953, 65, 304.

10 C. Martineau, M. Allix, M. R. Suchomel, F. Porcher, F. Vivet, C. Legein, M. Body, D. Massiot, F. Taulelle and F. Fayon, Dalton Trans., 2016, 45, 15565-15574.

11 R. D. Shannon, Acta Crystallogr., Sect. A: Cryst. Phys., Diffr., Theor. Gen. Crystallogr., 1976, 32, 751.

12 B. Henderson and G. F. Imbusch, Optical Spectroscopy of Inorganic Solids, Oxford University Press, 1989.
13 A. Lempicki, L. Andrews, S. J. Nettel, B. C. McCollum and E. I. Solomon, Phys. Rev. Lett., 1980, 44, 1234-1236.

14 D. Sekiguchi and S. Adachi, ECS J. Solid State Sci. Technol., 2014, 3, R60-R64.

15 Y. C. Chang, C. H. Liang, S. A. Yan and Y. S. Chang, J. Phys. Chem. C, 2010, 114, 3645-3652.

16 L. L. Wei, C. C. Lin, M. H. Fang, M. G. Brik, S. F. Hu, H. Jiao and R. S. Liu, J. Mater. Chem. C, 2015, 3, 1655-1660.

17 M. Y. Peng, X. W. Yin, P. A. Tanner, C. Q. Liang, P. F. Li, Q. Y. Zhang and J. R. Qiu, J. Am. Chem. Soc., 2013, 96, 2870-2876.

18 Y. H. Jin, Y. R. Fu, Y. H. Hu, L. Chen, H. Y. Wu, G. F. Ju, M. He and T. Wang, Powder Technol., 2016, 292, 74-79.

19 R. P. Cao, Y. J. Ye, Q. Y. Peng, G. T. Zheng, H. Ao, J. W. Fu, Y. M. Guo and B. Guo, Dyes Pigm., 2017, 146, 14-19.

20 D. Sekiguchi, J. Nara and S. Adachi, J. Appl. Phys., 2013, 113, 183516-183522.

21 W. L. Wu, M. H. Fang, W. L. Zhou, T. Lesniewski, S. Mahlik, M. Grinberg, M. G. Brik, H. S. Sheu, B. M. Cheng, J. Wang and R. S. Liu, Chem. Mater., 2017, 29, 935-939.

22 B. Wang, H. Lin, J. Xu, H. Chen and Y. S. Wang, ACS Appl. Mater. Interfaces, 2014, 6, 22905-22913.

23 L. Y. Wang, E. H. Song, Y. Y. Zhou, T. T. Deng, S. Ye and Q. Y. Zhang, J. Mater. Chem. C, 2017, 5, 7253-7261.

24 T. T. Deng, E. H. Song, J. Sun, L. Y. Wang, Y. Deng, S. Ye, J. Wang and Q. Y. Zhang, J. Mater. Chem. C, 2017, 5, 29102918.

25 M. Grinberg, Opt. Mater., 2002, 19, 37-45.

26 Z. Pan, Y. Y. Lu and F. Liu, Nat. Mater., 2012, 11, 58-63. 